\title{
Impacts of gambling problems on partners: partners' interpretations
}

\author{
Louise Holdsworth $^{\dagger}$, Elaine Nuske ${ }^{\dagger}$, Margaret Tiyce $^{*+}$ and Nerilee Hing ${ }^{\dagger}$
}

\footnotetext{
* Correspondence: margaret.tiyce@ scu.edu.au

${ }^{\dagger}$ Equal contributors

Centre for Gambling Education and Research, Southern Cross University, PO Box 157, Lismore, New South

Wales 2480, Australia
}

\begin{abstract}
Partners can be especially vulnerable to the negative effects of gambling problems, but little research has sought to understand partners' experiences from their own unique perspectives. This qualitative interpretive study explored the impacts of gambling problems on partners. In-depth interviews were conducted with 18 partners and ex-partners of people with gambling problems to understand their experiences of gambling problems from their perspectives. The findings showed that partners experienced a wide range of negative effects, especially on their financial security, their emotional, mental and physical health, and on their relationships. The financial impacts of gambling problems on partners were substantial and far-reaching. Some partners were forced to take up extra employment to cover household expenses and pay off gambling-related debts. Others lost their savings, homes, belongings and established ways of life. While these impacts were extensive, partners also experienced a range of emotional impacts that were equally devastating. Their gambling partner's lies, dishonesty and concealment of problems and gambling behaviour created considerable distress, loss of trust and a sense of betrayal. These experiences undermined these partners' sense of self-identity, and created additional conflicts within their relationships. Along with accumulating mental and physical health impacts, these challenges lead to separation and/or divorce for many participants. These findings point to the need for greater understanding of partners' experiences and public health initiatives that protect partners and their families from the harmful effects of gambling problems.
\end{abstract}

Keywords: Gambling problems, Negative impacts, Partners, Significant others

\section{Springer}

\section{Introduction}

While gambling is a well-accepted form of recreation and entertainment, some people develop gambling problems that have detrimental impacts, not only on themselves, but also on their partners, families, friends and communities (Hodgins, Shead \& Makarchuk, 2007; Petry \& Weiss, 2009; Patford, 2009; Productivity Commission, 2010). Partners of people with gambling problems can be especially vulnerable. The negative impacts of gambling problems on partners are known to include financial and material losses, psychological and social stresses, conflict in home life and relationships, as well as challenges coping with distressed children, dealing with legal and financial repercussions, and fulfilling other roles and responsibilities neglected by their partner (Abbott, Cramer \& Sherrets, 1995; Dixon-Swift, James \& Kippen, 2005; Grant 
Kalischuk, Nowatzki, Cardwell, Klein \& Solowoniuk, 2006; Krishnan \& Orford, 2002; Patford, 2008, 2009).

Little research, however, has focused on partners' psychological and emotional experiences from their own unique perspectives. Indeed, the wide range of issues and needs of partners of people with gambling problems have been long overlooked (Grant Kalischuk et al., 2006; Hodgins et al., 2007; Patford, 2009). Yet, understanding partner's experiences of problem gambling is important for the development of effective strategies that both assist people with gambling problems and protect their significant others (Evans \& Delfabbro, 2003). To address this research gap, this study investigated how gambling problems impact on partners' emotional, mental and physical health and wellbeing, from the partner's unique perspective.

\section{Background}

Research suggests that in countries with mature gambling markets, between $2 \%$ and $5 \%$ of the adult population may be engaged in problem or pathological levels of gambling (Productivity Commission, 2010; Volberg, 2007). People with gambling problems can experience considerable financial debt, physical and mental health problems, relationship breakdown, and legal and work-related problems as a result of their gambling (Hodgins et al., 2007; Productivity Commission, 2010; Patford, 2008; Pulford et al., 2009).

Significantly, these negative impacts are also recognised to extend beyond the person with gambling problems, and have negative consequences for their partners, children, family members, friends and communities (Abbott, 2001; Ciarrocchi \& Richardson, 1989; Darbyshire, Oster \& Carrig, 2001; Franklin \& Thoms, 1989; Gaudia, 1987; Ladouceur, Dub'e \& Bujold, 1994; Lesieur, 1998; Productivity Commission, 2010; Patford, 2009; Pulford et al., 2009; Tran, 1999). Indeed, between five and 17 people may be negatively affected by just one person's gambling problems (Hodgins et al., 2007; Ladouceur et al., 1994; Lesieur, 1998). Consequently, while gambling problems are experienced by only a small proportion of the population, the effects can be farreaching. As noted, relatively little research has investigated the nature and severity of these effects on partners and significant others (Chan, Jackson, Shek \& Dowling, 2012; Hodgins et al., 2007; Patford, 2009).

Amongst studies that have been conducted, Patford's $(2008,2009)$ research highlights the substantial negative effects problem gambling can have on partners and their children, including financial problems within the household, diminishing quality of life, emotional distress and health problems. In essence, Patford's $(2008,2009)$ research shows that problem gambling can profoundly disrupt family's lives. In reality, the financial, health and social impacts of problem gambling are considerable for partners and families of those with gambling problems (Hodgins et al., 2007; Petry \& Weiss, 2009; Productivity Commission, 2010).

Within the family, problem gambling is most often identified when financial resources fail to meet the demands of everyday household expenses, and fund gambling activities and gambling debts (Thomas \& Jackson, 2004). However, little research has actually examined the impact of gambling on family finances (Grant Kalischuk, 2010; Hodgins \& el-Guebaly, 2004; Slade \& McConville, 2003). Nevertheless, financial stress, debt, loan default, harassment by creditors, loss of property and lack of financial 
security are known to be issues for people with gambling problems (Grant Kalischuk, 2010). Particularly distressing for partners, the disclosure of financial problems or bankruptcy, and the loss of joint savings and/or assets to settle debts, can lead to profound disruptions to a family's lifestyle, sometimes necessitating an increase in paid work by the partner, sale of the family home, and downgrading of established lifestyles and activities (Dickson-Swift et al., 2005; Grant Kalischuk, 2010). Patford (2009) and Steinberg (1993) note that partners frequently take responsibility for many aspects of their gambling partner's lives even though these may be unfamiliar and difficult roles and responsibilities.

Furthermore, research shows that debt and other financial problems can contribute to negative effects on health and wellbeing, with links drawn, for example, between debt and problems with mental health (Dickerson, 1995; Grant Kalischuk, 2010; Patford, 2009) and physical health (Downs \& Woolrych, 2010; Grant Kalischuk, 2010). Patford's (2009) study of female partners, for example, concluded that dealing with a partner's gambling and related financial and legal problems can negatively affect a woman's physical and mental health through smoking, insomnia, over-eating, high blood pressure, panic attacks, fatigue and exhaustion. Similarly, Dickerson (1995) found that partners experience sleeping problems, stress-related problems, high levels of depressive symptoms, and other physical and emotional health problems.

Gambling problems can also lead to relationship breakdown, separation and divorce (Downs \& Woolrych, 2010). Key issues leading to relationship problems may include financial problems, breakdown of trust between the couple, and perceived lack of commitment to the relationship (Downs \& Woolrych, 2010). Patford (2009) similarly found that, for partners, loss of trust was amongst the most disturbing consequences of problem gambling. Indeed, Downs and Woolrych (2010) suggest that trust-breaking behaviour, such as dishonesty, lying, deceit and betrayal, underlies many of the relationship issues experienced by people with gambling problems and can lead to separation and divorce. Notwithstanding these challenges, some partners do remain with their gambling partner. According to Hodgins and el-Guebaly (2004), some partners remain to provide informal control of finances and support for their partner, even though they may have concerns about the loss of financial security and other negative consequences. Others stay because of love for the person, fear of being alone, a belief that staying is beneficial for their children, and/or lack of financial resources (Dickson-Swift et al., 2005). However, research in this area is limited.

Patford $(2008,2009)$ argues that far greater research is needed to understand the impacts of gambling problems on partners. Therefore, this study aimed to address this research gap by exploring the experiences of partners of people with gambling problems. The study sought in-depth understanding of partners' experiences from their own unique perspectives, including the impacts gambling had on their emotional, mental and physical health and wellbeing, and on their relationships and their broader lives.

\section{Methods}

An interpretive qualitative methodology (Charmaz, 2006; Denzin \& Lincoln, 2011; Patford, 2008, 2009), approved by the researchers' university Human Research Ethics Committee, was used to conduct the study. Interpretive qualitative research designs 
seek in-depth understanding of the multiple and subjective perceptions, meanings and experiences of individuals (Charmaz, 2006; Neuman, 2011). They aim to make participants' social worlds and lived experiences visible (Denzin \& Lincoln, 2011). The qualitative interpretive methodology was deemed appropriate for this study as the aim was to understand how partners experience the negative effects of gambling problems, from their own unique perspectives. Qualitative interpretive studies enhance understanding of individual experiences and expose key issues and concerns through in-depth description and narrative accounts (Clandinin \& Connelly, 2000; Neuman, 2011).

\section{Participants}

The study involved 18 partners and ex-partners of people with gambling problems from across Australia. This number of participants is considered appropriate in interpretive qualitative designs (Minichellio, Aroni, Timewell \& Alexander, 1990; Rubin \& Rubin, 1995) and in similar gambling research (Darbyshire, Oster \& Carrig, 2001; Downs \& Woolrych, 2010; Patford, 2008, 2009). Six participants were recruited from a previous gambling study conducted by some of the authors, six through Facebook and Google advertisements, three through a gambling support group and two through personal contacts. Participants ranged in age from 22 to 68 years. Seventeen were women and one was a man. At the time of the interview, ten participants were in a continuing relationship with their partner, while eight were separated and/or divorced.

\section{Procedures}

Qualitative, in-depth, semi-structured interviews were conducted consistent with qualitative research designs (Minichellio, Aroni, Timewell \& Alexander, 1990; Rubin \& Rubin, 1995). Seventeen interviews were conducted by telephone and one was conducted face-to-face, between January and April 2012. One of the authors, a qualified social worker, conducted the interviews. Due to the sensitive nature of topics discussed, the length of each interview was determined by individual participants (Rubin \& Rubin, 1995), with most interviews lasting between 45 and 60 minutes. The interviews were guided by an interview schedule containing broad themes as prompts (Minichellio et al., 1990, Neuman, 2011). Interviews were digitally recorded and later professionally transcribed.

Participants were asked about their experiences of their partner's gambling problems and how their partner's gambling impacted on them and their lives. The study focused on participants' own subjective perceptions of their experiences (Charmaz, 2006; Denzin \& Lincoln, 2011; Neuman, 2011). Thus, reported experiences of, for example, 'depression' and 'anxiety' constituted participants' personal perceptions and interpretations. An objective psychological diagnosis was not relevant or required. The experiences and the understandings participants had, and the meanings they attributed to these experiences were important, providing a critical window of understanding into their personal experiences and lives (Denzin \& Lincoln, 2011).

\section{Analysis}

Thematic Analysis (Braun \& Clarke 2006, Guest, 2012) was used to analyse the interview data. Founded in Grounded Theory (Glaser and Strauss, 1967), Thematic Analysis 
is a theoretically flexible and widely accepted and utilised method enabling meaningful patterns within the data to be identified, analysed and reported in rich descriptive detail (Braun \& Clarke 2006, Guest, 2012). This approach enabled key ideas, meanings and understandings to be explicated through the analysis process, while preserving participants' constructions of their own narrative accounts in the results (Braun \& Clarke 2006; Charmaz, 2006; Clandinin \& Connelly, 2000).

The qualitative data analysis software package, NVivo, was also utilised to organise the data, assist the coding process and clarify patterns in the data. Using an inductive approach, coding and analysis was carried out independently by three of the researchers to increase inter-coder reliability and research rigour (Boyatzis, 1998; Fereday \& MuirCochrane, 2006; Guest, 2012). The analysis extended beyond identifying semantic phrases or words in the data by further identifying, interrogating and explicating underlying latent ideas and meanings related specifically to the research question (Boyatzis, 1998; Guest, 2012). Individual participants narratives were also analysed in their entirety to avoid the loss of meaning that can occur when thematic analysis is used in its simplest form (Guest, 2012). Accordingly, participants' narratives are highlighted in the findings that follow, with pseudonyms used for anonymity.

\section{Results}

For the partners in this study, the negative effects of their partner's gambling problems centred on four key areas - financial loss, emotional distress, impairment of mental and physical health, and erosion of their partner relationship. As the following findings show, issues around financial losses, and the way in which they were handled, were interwoven with many of the complex and compounding additional effects partners experienced.

\section{Financial impacts on partners}

Participants all highlighted their dire financial situation and the difficulties of coping with their partner's financial losses and gambling debts. Many spoke about not being aware of the financial consequences of their partner's gambling, until a financial or legal crisis emerged. For instance, Bridget and Jill explained:

So I look back now and I think, 'that's why we had no money', I put two and two together. But he was telling me that there were bills and there was no way of knowing there were [gambling] debts of $\$ 1,000$ every month (Bridget).

... he kept his finances secret. I didn't know about his gambling problem and I didn't know about the debt. Then, I came across some paperwork, it was bankruptcy paperwork, so it was pretty bad (Jill).

Participants experienced unrecognised debt, financial losses, pressure from debt collectors, and financial insecurity. Many participants disclosed their partner had gambled savings they believed to be secure. This impacted not only on partners but also on their children. Some lost their savings, assets, homes and/or belongings. All suffered disruption and deterioration of their established ways of life and their sense of stability and security. Tess commented: 
I've lost my life savings because of gambling and I had lots of plans. I wanted to run a business .... and now I'm in a situation where, I'm nearly 50 and I'm going to have to work 12 hour days just to be able to provide some sort of security (Tess).

Some partners were expected to provide financial support for their gambling partner, whether financing their gambling activities, paying off debts, or funding their contribution to household expenses, and this commonly meant increasing their employment and income to cover gambling losses. All partners took on additional roles and responsibilities as they attempted to address the gambling-related problems and ward off additional negative impacts on themselves and their family. Some took steps to ensure their personal finances were secure; others took control of the household finances. This was challenging and stressful for participants like Joanna who had never managed the household finances before. Nonetheless she asserted:

In the end it came down to me making sure all the money was out of his debit card account. I had to take on the whole burden of the finances, so I was in control of his account and in control of his money (Joanna).

The financial impacts of gambling problems on the partners in this study were substantial, detrimental and far-reaching, affecting their financial security and their relationships. The emotional impacts, however, were described as equally devastating.

\section{Impacts on emotional wellbeing}

The 'discovery' of gambling problems, particularly the financial losses gambling produced, generated strong emotional responses of distress and suffering for all study participants. Leanne, for example, observed 'When I found out I was shattered', while Joanna revealed:

The most extreme emotions came out of me. A lot of crying, and crying to the point of hyperventilation. I'd come home - all I'd do was cry all night. I'd go to work - I would be crying at work (Joanna).

It took some time for all participants to become aware of the full extent of their partner's gambling-related problems, and their emotional suffering was exacerbated by the way the gambling problems had been kept hidden. Maureen, for example, described being 'very, very hurt'. This emotional suffering typically intensified over time as more problems became apparent and efforts to address them became more difficult and/or were frustrated. Amy, for example commented, 'I was at my wit's end. I was a wreck, an absolute wreck', while Barbara said:

When I found out he was gambling, oh I was gutted, devastated, because I was working, supposedly, for us to get ahead in life. ... Just the lies, and the betrayal, and the broken promises (Barbara).

Consequently, emotional distress was often accompanied by feelings of anger, frustration and resentment, both overt and less apparent. Gail, for example, recalled 'I was 
angry. I was angry every single second of every single day', while Keira, declared, 'I wanted to delete all the pictures of him. ... I wanted to wring his neck!'

Emotions of fear also permeated participants' accounts. Leanne and Keira, for example, described feeling 'terrified' by the uncertainty and instability that had entered their lives. Others expressed fear related to 'issues of safety'. Christine, for example, described her situation as so 'frightening and confronting' that she 'felt like she was chained and drowning'. Similarly Gail stressed:

It was like trying to stop a tidal wave. Fear, incredible fear and issues of safety. ... Fear for your life. Fear for the future. I would be shaking with anger as I went through his stuff ... there was the fear of finding something. I was a mess (Gail).

Some participants worried they may have played a part in encouraging their partner's gambling or gambing problems, most often through their lack of awareness. This created guilt and self-blame, as Leonnie bemoaned, 'You take on so much blame, so much guilt'. For some participants this sense of guilt and shame was related to the negative impacts their children had also endured because of the gambling problems.

Participants' sense of self and identity was also negatively affected by their partner's gambling. Some participants, like Yasmine, Christine and Bridget, felt embarrassment and shame because of the social stigma attached to problem gambling, or as Christine noted the social stresses of 'holding this big secret'. Other particpants discussed the negative effects on their self-esteem. Leonnie, for example, claimed 'your self-esteem goes out the window', while Bridget observed, 'you feel like you're a failure, you feel like you're no good, ... an idiot, stupid. Your self-esteem is extremely low'. Gail explained:

Your self-confidence, I think, just gets destroyed. ... I would go through his stuff to see if he was still gambling. I became the worse version of myself. I became someone who I hated (Gail).

For partners in this study, shock, panic, distress, anger, fear, guilt and embarrasment were powerful emotional responses to their partner's gambling problems. These responses not only impacted negatively on their sense of self, self-esteem and identity but also lead to mental and physical health symptoms.

\section{Impacts on mental and physical health}

Alongside emotional issues, participants also reported suffering mental and physical health symptoms resulting from their partner's gambling problems. While experiences varied, mental health symptoms were predominatly associated with stress (and distress), anxiety and depression. Some participants revealed how stress and anxiety related to the gambling problems compromised their ability to work and their mental and physical health. Barbara observed:

I [felt like I] couldn't go to work, but I had to work. And I'd be at work thinking 'where is he? Is he working? ... or is he playing the pokies?' I was getting palpitations, I was a nervous wreck, anxious and depressed. 
Stress and anxiety also affected sleeping patterns and lead to detrimental life changes. For example, Gail remarked, 'I just remember being disassociated from my children, from my life. I was so stressed'. Equally, Leanne argued her anxiety and worry were so intense she had 'stopped eating and stopped sleeping', while Kath explained she 'had trouble sleeping and started smoking' because of 'all the worrying'.

Diagnosed depression and depressive thoughts were also reported by some participants. Joanne, Christine and Gail talked about the difficulty of coping with their partner's gambling and the stress and depression it created. Barbara, Gail and Joanna emphasised the negative effects high levels of stress had on their physical health. Joanna added:

I don't believe I slept more than three or four hours a night. Doctors told me my blood pressure was too high and they would put me on medication (Joanna).

Correspondingly, mental health issues had damaging repercussions for physical health, relationships and the ability to function in wider areas of life. Emphasising the pressures and stresses these compounding issues placed on physical and mental capacities to cope, Barbara commented, 'I've lain in bed of a weekend, and haven't been able to get out of bed. I was just physically and emotionally exhausted'. For most participants in this study, emotional, mental and physical health symptoms were not only compounding in nature, but could also be long-lasting. Some participants revealed that, despite leaving their partner, they continued to suffer related mental and physical health problems.

\section{Effects on relationships}

For all participants, their partner's gambling problems, alongside frustrated efforts to address them, had negative impacts on their partner relationships. Participants revealed how, once uncovered, gambling and its associated problems occupied a prominent position within their relationship. Jill explained:

Gambling drives a wedge in your relationship and pulls it apart, and it becomes destructive. You feel like they're being unfaithful to you, because it takes up such a huge part of the relationship (Jill).

A growing sense of disconnection and isolation occurred because of the time and resources spent on gambling. However, relationships were also eroded by dishonesty and lies. Leonie and Maureen stressed:

When I found out we started fighting a lot. It was the hurt of him lying. It wasn't the first time that he had lied about gambling. But then he started blaming me (Leanne).

... the lies and the cheating. The lies around what he does and doesn't do with this money. That affected the relationship the most in the long run (Maureen).

Similarly, Barbara emphasised her relationship was worn down by 'the lies and the betrayal and the broken promises'. Dishonesty, lies and loss of trust lead to feelings of betrayal for most participants. As Laurie emphasised, 'trust is the most important thing 
and [my partner] breached that position of trust and loyalty'. Maureen and Joanna added:

I've been with this man for 23 years and have done so much and given him so much, and he's still shown me no respect (Maureen).

I lost faith in him. I lost trust in him. I felt he was very dishonest and disloyal ... he was putting the gambling over the relationship. It tore our relationship apart on almost every level possible because there was just no trust whatsoever (Joanna).

The notion of shared dreams, 'promises' and mutual respect that accompany commitments to intimate partner relationships were perceived to be disrespected and undermined by the gambling behaviour of partners. Relationship changes were evident in all participants' accounts. Dominant among these was the perceived need to take responsibility for family and household matters, a feeling of increasing disconnection and a conscious decision to either leave the partner, or to stay.

In summary, the reported negative impacts of gambling problems, from partners' perspectives, were considerable and included extensive emotional, psychological, physical and relationship impacts, many of which have been previously unexplored in gambling research. The reported impacts are summarised in Table 1, below. Rather than being separate experiences, these negative experiences were most often compounding and inter-related, impacting on partners' ability to function in their work roles, relationships, homes and everyday lives.

\section{Discussion}

Several important and innovative findings emerged from this research, most notably the detrimental impacts that gambling problems had on partners' emotional wellbeing, their mental and physical health and their relationships. A common pattern in partners' narratives was the discovery of gambling problems through a financial crisis or event. Many partners explained that they were unaware their partner had gambling problems until financial stresses, debt or bankruptcy were revealed. Thomas and Jackson (2004) concur that financial problems are a typical signifier of gambling problems. These financial problems undermined participants' financial security and lead to emotional suffering and related harmful health symptoms. Participants spoke about the considerable difficulties they faced because of financial and related legal problems. Several partners had to increase their employment to compensate for their partner's gambling-related debt and loss of household income and savings. These findings align with other studies, such as Dickson-Swift et al.'s (2005) research that showed partners may experience considerable loss of financial security, personal assets and their established standard of living to reconcile gambling debts and manage household expenses.

The discovery of their partner's gambling problems was extremely distressing for partners and generated many additional problems, a finding similarly noted in other research (Dickson-Swift et al., 2005; Grant Kalischuk, 2010). Distress and emotional suffering were evident in all participant responses. All initially experienced shock, with many saying they did not understand the reasons for their partner's gambling and why they couldn't simply control it. These participants experienced their 
Table 1 Reported negative impacts of gambling problems on partners

\begin{tabular}{|c|c|c|c|}
\hline Financial impacts & Emotional impacts & Health impacts & Relationship impacts \\
\hline Loss of money/ savings & Distress & Stress & Loss of shared time \\
\hline Loss of assets, home & Anger & Coping difficulties & Disconnection \\
\hline Financial pressures & Frustration & Anxiety & Lies \& dishonesty \\
\hline Debt/ poverty & Guilt \& self-blame & Dissociation & $\begin{array}{l}\text { Loss of shared resources } \\
\& \text { goals }\end{array}$ \\
\hline Harassment by creditors & Emotional suffering & Depression & $\begin{array}{l}\text { Disruption of shared } \\
\text { understandings }\end{array}$ \\
\hline Bankruptcy & Panic & Loss of sleep & Arguments \\
\hline Legal issues & $\begin{array}{l}\text { Fear \& safety } \\
\text { concerns }\end{array}$ & $\begin{array}{l}\text { Impaired } \\
\text { functioning }\end{array}$ & Blaming \\
\hline $\begin{array}{l}\text { Diversion of funds from household } \\
\text { expenses }\end{array}$ & Loss of trust & Eating disorders & Loss of respect \\
\hline Loss of financial security & Feelings of betrayal & Smoking & Loss of trust \\
\hline Loss of quality of life & Isolation & Heart palpitations & Loss of cohesion \\
\hline $\begin{array}{l}\text { Taking on increased employment } \\
\text { \& income }\end{array}$ & Insecurity \& instability & Medicalisation & Distressed children \\
\hline \multirow[t]{4}{*}{$\begin{array}{l}\text { Taking on extra roles \& } \\
\text { responsibilities }\end{array}$} & Embarrassment & $\begin{array}{l}\text { High blood } \\
\text { pressure }\end{array}$ & Separation/divorce \\
\hline & Shame \& stigma & $\begin{array}{l}\text { Physical } \\
\text { exhaustion }\end{array}$ & \\
\hline & $\begin{array}{l}\text { Erosion of self \& } \\
\text { identity }\end{array}$ & $\begin{array}{l}\text { Emotional } \\
\text { exhaustion }\end{array}$ & \\
\hline & & Other symptoms & \\
\hline
\end{tabular}

partner's lies, dishonesty and concealment of gambling activities and problems as betrayal and a loss of trust. These experiences contributed to a growing disconnection and isolation for partners that was not always aided by support from family and friends because of feelings of embarrassment and shame, and the pervasiveness of stigma surrounding gambling problems. Manifestations of distress and 'extreme emotions' were evident in accounts of crying, shock and anger that were seemingly worsened by feelings of guilt, self-blame and shame. Some partners also expressed fear, not only for their future security, but also for their personal safety and that of their children.

The emotional distress experienced when gambling and financial problems were revealed led to negative mental and physical health impacts for many partners. Alongside acute distress, mental health issues of ongoing stress, dissociation, anxiety, depression and emotional exhaustion were reported, along with physical health concerns of sleeping and eating problems, smoking, exhaustion, heart palpitations and high blood pressure. These findings are comparable with other research that has suggested problem gambling impacts on the health of partners and family members (Abbott, 2001; Dickson-Swift et al., 2005; Downs \& Woolrych, 2010; Gaudia, 1987; Grant Kalischuk, 2010; Lesieur, 1998; Lorenz \& Yaffee, 1988; Lorenz \& Shuttleworth, 1983; Patford, 2009).

Partners' relationships were also impacted significantly by the gambling problems and the ways in which they were managed. The eight participants who had separated from or divorced their partner spoke about the breakdown of trust resulting from the 
partner's lies, dishonesty and betrayal, most often related to concealing gambling activities and gambling problems. Research has shown that it is not uncommon for gambling problems to lead to separation and divorce (Lorenz \& Shuttleworth, 1983; Lorenz \& Yaffe, 1988) and in this regard, breakdown of trust can be a central issue in relationship breakdown (Downs \& Woolrych, 2010). Conversely, ten partners were still in their relationship, with several explaining that they stayed to manage the household finances and to support their partner. However, they too experienced distress, loss of trust and a sense of betrayal, a finding aligning with other research (for example, Dickson-Swift et al., 2005; Hodgins \& el-Guebaly, 2004).

The current study found that financial problems associated with gambling often became apparent first, which over time lead to and compounded emotional, mental and physical health, and relationship problems. Financial problems were major concerns for participants. However, the disruption of family life, of established ways of living and being as a couple, and of well-laid plans and future aspirations created experiences of extreme emotional distress and upheaval. The disruption of taken-for-granted assumptions about their relationship and their jointly conceived future created uncertainty and instability as their lives were fractured and thrown into disarray. The ensuing emotional distress lead to mental and physical health problems, and adjustment by some partners of their relationship status.

While the financial impacts of gambling problems on partners and families are known to be detrimental and far-reaching, the emotional impacts are not yet fully understood. Thus, this research makes an important contribution to knowledge in this field by exposing and highlighting the magnitude of emotional, psychological and physical impacts of gambling problems on partners' from their own perspectives. What this research suggests is that the emotional, psychological and physical impacts of a partner's gambling problems may be as devastating and disruptive for individuals as the financial impacts, eroding their health and wellbeing, their sense of self and identity, their relationships and the quality of their present and future lives. As one study participant, Gail, emphasised, 'It's not just the money, it's the whole - because you're a family. It's that whole ...your whole life is effected'.

\section{Conclusions}

Partners of people with gambling problems may experience many negative impacts as a result of their partner's gambling. Consistent with other research, this qualitative study with 18 partners and ex-partners found that gambling problems created undue financial stresses and strains that impacted on partners' financial security and the quality of their lives. Additionally, the research also showed that gambling problems created considerable negative impacts on partners' emotional wellbeing, shaping experiences of distress, frustration, fear and other emotional responses which affected their ability to function and cope with the demands of their situations and their everyday lives. This, in turn, lead to mental and physical health symptoms and contributed to growing challenges and conflicts in their relationships, which for some resulted in separation or divorce. Throughout these experiences, many partners felt isolated and distanced from the kinds of help they reportedly needed. 
These research findings suggest opportunities may exist to minimise these negative impacts on partners through more timely and practical assistance. This recommendation has been raised by previous researchers advocating improved support for partners of problem gamblers (Krishnan \& Orford, 2002), and to better equip partners engaged in support and problem gambling resolution processes (Evans \& Delfabbro, 2003; Hodgins et al., 2007; Pulford et al., 2009). However, this research suggests partner support also needs to extend to assisting partners with their emotional, psychological and physical health and wellbeing issues, along with the myriad of other personal concerns they experience, but which may not be captured in more quantitative research designs. Developing a range of efficacious self-help measures, particularly those centred on financial management and emotional resilience may go some way in ameliorating the negative impacts partners endure. Although far greater research is needed to clarify the types of assistance that would be of greatest benefit, some partners suggested improving access to information and support services for partners and families was important.

This study contributes to the developing research on the negative impacts of gambling problems on partners by providing further insight into the emotional, psychological, physical health and wellbeing, and relationship issues partners may experience. However additional research would be advantageous to further understand these issues and how they might be effectively addressed through gambling services and public health initiatives. The small sample of partners in this study were predominately female and Australian and further research may reveal more varied responses and issues important in understanding and addressing partners' impacts, especially across different populations and contexts. Additionally, the character and severity of gambling problems was not measured and further research might compare such measures to the depth of impacts on partners and families. The research also revealed that children in these families suffered negative impacts alongside partners, and the concerns of children, as well as families, friends and communities, are also important to consider in future research designs. Substantial gaps in the research exist on the effects of gambling problems on partners' emotional health and wellbeing and this area requires far greater attention. More generally, research on partners' experiences, impacts and needs has been limited. However, understanding and supporting partners of people with gambling problems is critical in safeguarding their health and wellbeing, and that of their families and communities.

Competing interests

The authors declare that they have no competing interests.

Authors' contributions

All authors contributed equally to this research and the paper produced here. All authors read and approved the final manuscript.

\section{Acknowledgements}

The authors would like to thank the gambling help services that provided assistance with recruitment and the study participants themselves for sharing their stories and insights. This research was funded by an Internal Research Grant from the School of Tourism and Hospitality Management, Southern Cross University, Lismore, Australia. 


\section{References}

Abbott, MW. (2001). What do we know about gambling and problem gambling in New Zealand? Report No. 7 of the New Zealand Gaming Survey. Wellington, New Zealand: Department of Internal Affairs. Retrieved 30 July 2012, from www.austgamingcouncil.org.au/images/pdf/eLibrary/631.pdf.

Abbott, DA, Cramer, SL, \& Sherrets, SD. (1995). Pathological gambling and the family-practice implications. Families in Society, 76(4), 213-219.

Boyatzis, R. (1998). Transforming qualitative information: Thematic analysis and code development. Thousand Oaks, CA: Sage. Braun, V. \& Clarke, V. (2006). Using thematic analysis in psychology. Qualitative Research in Psychology, 3(2), 77-101.

Chan, EM, Jackson, A, Shek, D, \& Dowling, N. (2012). Problem gambling and family violence in Chinese problem gamblers: Prevalence, impact and coping. Paper presented at the First Asia Pacific Conference on. Macao: Gambling \& Commercial Gaming Research.

Charmaz, K. (2006). Constructing Grounded Theory. London: Sage.

Ciarrocchi, J, \& Richardson, R. (1989). Profile of compulsive gamblers in treatment: Update and comparisons. Journal of Gambling Behavior, 5, 53-65.

Clandinin, D, \& Connelly, F. (2000). Narrative inquiry: Experiences and story in qualitative research. San Francisco: Jossey-Bass Publishers.

Commission, P. (2010). Gambling, Productivity Commission inquiry report. (No. 50). Canberra: Australian Government Productivity Commission.

Darbyshire, P, Oster, C, \& Carrig, H. (2001). The experience of pervasive loss: Children and young people living in a family where parental gambling is a problem. Journal of Gambling Studies, 17, 23-45.

Denzin, N, \& Lincoln, YS. (2011). The discipline and practice of qualitative research. In N Denzin \& Y Lincoln (Eds.), The Sage Handbook of Qualitative Research (pp. 1-19). Thousand Oaks, CA: Sage.

Dickerson, MG. (1995). Problem gambling: Future directions in research, treatment, prevention and policy initiatives. In J O'Connor (Ed.), High Stakes in the Nineties, Proceedings of the Sixth National Conference of the National Association of Gambling Studies (pp. 73-86). Fremantle: National Association for Gambling Studies.

Dickson-Swift, VA, James, EL, \& Kippen, S. (2005). The experiences of living with a problem gambler: Spouses and partners speak out. Journal of Gambling Issues, 13. Retrieved 30 July 2012, from http://www.camh.net/egambling/issue13/.

Downs, C, \& Woolrych, R. (2010). Gambling and debt: The hidden impacts on family and work life. Community, Work \& Family, 13(3), 311-328.

Evans, L, \& Delfabbro, L. (2003). Perceptions of service efficacy and individual differences in help-seeking strategies amongst South Australian problem gamblers. Gambling Research, 15(2), 44-57.

Fereday, J, \& Muir-Cochrane, E. (2006). Demonstrating rigor using thematic analysis: a hybrid approach of inductive and deductive coding and theme development. International Journal of Qualitative Methods, $5(1), 1-11$.

Franklin, J, \& Thoms, DR. (1989). Clinical observations of family members of compulsive gamblers. In H Shaffer (Ed.), Compulsive gambling: Theory, research and practice (pp. 135-146). Toronto, ON: Lexington Books.

Gaudia, R. (1987). Effects of compulsive gambling on the family (pp. 254-256). May-June: Social Work.

Glaser, B, \& Strauss, A. (1967). The discovery of Grounded Theory: Strategies for qualitative research. Chicago: Aldine.

Grant Kalischuk, RG. (2010). Co-creating life pathways: problem gambling and its impact on families. The Family Journal, 18(1), 7-17.

Grant Kalischuk, RG, Nowatzki, N, Cardwell, K, Klein, K, \& Solowoniuk, J. (2006). Problem gambling and its impact on families: a literature review. International Gambling Studies, 6(1), 31-60.

Guest, G. (2012). Applied Thematic Analysis. Thousand Oaks, California: Sage.

Hodgins, DC, \& El-Guebaly, N. (2004). Retrospective and prospective reports of precipitants to relapse in pathological gambling. Journal of Consulting and Clinical Psychology, 72(1), 72-80.

Hodgins, DC, Shead, NW, \& Makarchuk, K. (2007). Relationship satisfaction and psychological distress among concerned significant others of pathological gamblers. The Journal of Nervous and Mental Disease, 195(1), 65-71.

Krishnan, M, \& Orford, J. (2002). Gambling and the family: from the stress-coping-support perspective. International Gambling Studies, 2, 61-83.

Ladouceur, R, Dub'e, D, \& Bujold, A. (1994). Prevalence of pathological gambling and related problems among college students in the Quebec Metropolitan area. Canadian Journal of Psychiatry, 39, 289-293.

Lesieur, HR. (1998). Costs and treatment of pathological gambling. The Annals of the American Academy, 556, 153-171.

Lorenz, VC, \& Shuttlesworth, DE. (1983). The impact of pathological gambling on the spouse of the gambler. Journal of Community Psychology, 11, 67-76.

Lorenz, VC, \& Yaffee, RA. (1988). Pathological gambling: Psychosomatic, emotional and marital difficulties as reported by the spouse. Journal of Gambling Behavior, 4, 13-26.

Minichellio, V, Aroni, R, Timewell, E, \& Alexander, L. (1990). In-depth interviewing: Researching people. Melbourne: Longman Cheshire.

Neuman, WL. (2011). Social research methods (7th ed.). Boston: Pearson/Allyn \& Bacon.

Patford, JL. (2008). For poorer: how men experience, understand and respond to problematic aspects of a partner's gambling. Gambling Research, 19(1 \& 2), 7-20.

Patford, JL. (2009). For worse, for poorer and in ill health: how women experience, understand and respond to a partner's gambling problems. International Journal of Mental Health and Addiction, 7, 177-189.

Petry, N, \& Weiss, M. (2009). Social support is associated with gambling treatment outcomes in pathological gamblers. American Journal of Addiction, 18(5), 402-408.

Pulford, J, Bellringer, M, Abbott, M, Clarke, D, Hodgins, D, \& Williams, J. (2009). Barriers to help-seeking for a gambling problem. Journal of Gambling Studies, 25, 33-48.

Rubin, H, \& Rubin, I. (1995). Qualitative interviewing: The art of hearing data. Thousand Oaks, CA: Sage. 
Slade, P, \& McConville, C. (2003). The problem with problem gambling: historical and economic concerns. Journal of Economic and Social Policy, 8(1). Retrieved 30 July 2012, from http://epubs.scu.edu.au/jesp/vol8/iss1/1.

Steinberg, M. (1993). Couples treatment issues for recovering male compulsive gamblers and their partners. Journal of Gambling Studies, 9(2), 153-167.

Thomas, SA, \& Jackson, AC. (2004). Influences on gambling behaviours and outcomes: a model for the design of effective interventions. Gambling Research, 16(2), 40-51.

Tran, D. (1999). Asian gambling ... family losses: A study of gambling related violence in the Vietnamese community. Richmond, Victoria, Australia: Jesuit Social Services.

Volberg, RA. (2007). Population surveys. In G Smith, DC Hodgins, \& RJ Williams (Eds.), Research and Measurement Issues in Gambling Studies (pp. 33-54). Burlington MA: Academic Press.

doi:10.1186/2195-3007-3-11

Cite this article as: Holdsworth et al:: Impacts of gambling problems on partners: partners' interpretations. Asian

Journal of Gambling Issues and Public Health 2013 3:11.

Submit your manuscript to a SpringerOpen ${ }^{\circ}$ journal and benefit from:

- Convenient online submission

- Rigorous peer review

- Immediate publication on acceptance

- Open access: articles freely available online

- High visibility within the field

- Retaining the copyright to your article

Submit your next manuscript at $\gg$ springeropen.com 